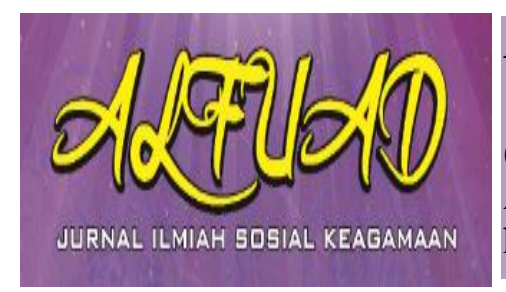

ALFUAD JOURNAL, 4 (2), 2020,(15-26)

(E-ISSN 2714-7606 P-ISSN 2614-4786 )

Available online at

http://ecampus.iainbatusangkar.ac.id/ojs/index.php/alfuad

\title{
MENGKRITISI MODEL KONSELING BERBASIS BUDAYA NUSANTARA: MODEL KIPAS
}

\section{Zulfikar*)}

STKIP PGRI Sumatera Barat,

Indonesia

E-mail: zulfikar.bk@gmail.com

\section{Zubaidah}

Institut Agama Islam Negeri Batusangkar, Indonesia

E-mail: zhubaidah09@gmail.com

*) Corresponding Author

\begin{abstract}
The presence of the KIPAS model is an effort to strengthen the dignity of Indonesian counselors and counselors who have been oriented towards western culture. Western culture which is clearly incompatible with our culture, Nusantara culture which adheres to eastern culture. The attraction of the BK Model KIPAS is the use of cultural values as the basis for implementing $B K$ services, thus giving rise to an enlightenment in the implementation of $B K$ services in the archipelago. This gives an enthusiasm and hope that the idea of a counseling model based on this archipelago culture will be accepted now and especially in the future. The model is an acronym for KIPAS, which is intensive and progressive counseling that is adaptive to structure. The existence of the KIPAS model will be able to answer problems that occur such as the many unresolved student problems and improvements to the image of BK in society. So far, we have seen that the implementation of counseling guidance services in schools in Indonesia has become something student dislike. As a new model in the world of BK, of course it cannot be separated from the strengths or strengths and weaknesses or weaknesses of the KIPAS model itself. The KIPAS model should accommodate all cultures in Indonesia from Sabang to Merauke.
\end{abstract}

Keywords: Counseling, Indonesian Culture, KIPAS

\section{PENDAHULUAN}

BK (BK) merupakan bagian yang tak terpisahkan dari pendidikan dan mempunyai tanggung jawab yang amat besar dalam mewujudkan manusia Pancasila yang sesuai dengan tujuan dari pendidikan Nasional. BK ditinjau dari tujuan pendidikan Nasional baik secara konseptual maupun operasional, yaitu keseluruhan upaya bimbingan yang bertitik tolak dari hakekat pendidikan Nasional yakni dalam mencerdaskan kehidupan manusia, dan membantu terbimbing dalam mewujudkan diri sebagai manusia Pancasila (Walgito, 2004: 11).

Layanan BK di Indonesia sendiri dirintis sejak tahun 1960, yang kemudian pada kurikulum 1975 pelayanan BK secara resmi memasuki SD, SLTP, SLTA. Pada kurikulum 1984 keberadaan BK lebih digalakkan lagi di sekolah-sekolah (Prayitno, 1994:29). Tujuan BK sendiri adalah untuk membantu individu agar dapat mencapai perkembangan secara 
optimal sesuai dengan bakat, kemampuan, minat dan nilai-nilai, serta terpecahkannya masalah-masalah yang dihadapi individu. Maka dari itu, tujuan dari pelayanan BK ialah supaya orang yang dilayani dalam hal ini adalah siswa menjadi mampu mengatur kehidupannya sendiri, memiliki pandangannya sendiri, mengambil sikap sendiri dan berani bertanggung jawab serta konsekuensi dari tindakan-tindakannya.

Selama ini kita melihat bahwa pelaksanaan pelayanan bimbingan konseling di sekolah di Indonesia menjadi sesuatu hal kurang disenangi oleh siswa. BK adalah suatu momok yang menakutkan. Berhadapan dengan guru BK adalah sesuatu hal yang perlu dihindari. Guru BK dilabeli sebagai polisi sekolah yang mengurusi siswa nakal dan suka membolos. Kebanyakan siswa sudah terlanjur tidak senang dan bahkan 'alergi' dengan bimbingan konseling. Baik dari segi kepribadian konselor atau guru BK yang merupakan pelaksana dari pelayanan BK maupun dari segi keefektifan pelayanan BK itu sendiri. Tak jarang guru BK mendapatkan penilaian yang kurang baik, (Batuadji, 2015: 19) guru BK menghadapi permasalahan lain seputar persepsi siswa yang negatif terhadap mereka.

Keefektifan pelayanan BK itu sendiri, terlihat dari sejauh mana keefektifan fungsi BK itu sendiri.
Sebagaimana yang disimpulkan oleh (Batuadji, 2015: 23) bahwa efektivitas fungsi BK memiliki keterkaitan dengan persepsi siswa terhadap BK. Jika persepsi terhadap efektivitas fungsi BK positif, yang berarti bahwa BK menjalankan fungsinya secara efektif, maka persepsi siswa terhadap BK akan cenderung positif, sebaliknya jika persepsi terhadap efektivitas fungsi BK negatif, yang berarti bahwa BK belum menjalankan fungsinya secara efektif, maka persepsi siswa terhadap BK akan cenderung negatif.

Pelaksanaan pelayanan BK yang selama ini diterapkan di sekolah di Indonesia adalah berasal dari Amerika atau barat yang memang cocok diterapkan oleh konselor pada siswa Amerika. Namun, ternyata tidak terlalu cocok untuk dipraktikkan dalam hal pemecahan masalah pada siswa Indonesia. Mengingat masyarakat Indonesia termasuk siswa yang lebih menganut budaya timur memiliki berbagai macam etnis dan budaya yang berbeda satu sama lain. Palmer and Laungani (2008: 97) berpendapat bahwa budaya-budaya barat menekankan individualisme, kognitifisme, bebas, dan materialisme, sedangkan budaya timur menekankan komunalisme, emosionalisme, determinisme, dan spiritualisme.

Pengajuan model berpusat pada budaya didasarkan pada suatu kerangka 
pikir (framework) korespondensi budaya konselor dan konseli. Diyakini, sering kali terjadi ketidaksejalanan antara asumsi konselor dengan kelompok-kelompok konseli tentang budaya, bahkan dalam budayanya sendiri. Konseli tidak mengerti keyakinan-keyakinan budaya yang fundamental konselornya demikian pula konselor tidak memahami keyakinankeyakinan budaya konselinya. Atau bahkan keduanya tidak memahami dan tidak mau berbagi keyakinan-keyakinan budaya mereka.

Oleh sebab itu pada model kajian budaya menjadi pusat perhatian. Artinya, fokus utama model ini adalah pemahaman yang tepat atas nilai-nilai budaya yang telah menjadi keyakinan dan menjadi pola perilaku individu. Dalam konseling ini penemuan dan pemahaman konselor dan konseli terhadap akar budaya menjadi sangat penting. Dengan cara ini mereka dapat mengevaluasi diri masing-masing sehingga terjadi pemahaman terhadap identitas dan keunikan cara pandang masing-masing.

Beranjak dari fenomena ini maka ditawarkan dan dihasilkan sebuah model konseling berbasis budaya nusantara. Hal ini memberikan suatu semangat dan pengharapan bahwa pemikiran mengenai model konseling berbasis budaya nusantara ini akan dapat diterima sekarang dan lebihlebih untuk masa depan. Sebuah tawaran yang telah dihasilkan tersebut mengenai model pelaksanaan pelayanan $\mathrm{BK}$ yang disebut sebagai model KIPAS yang digagas oleh Prof. Dr. Andi Mappiare-AT, M.Pd. Model tersebut diakronimkan menjadi KIPAS yaitu konseling intensif dan progresif yang adaptif terhadap struktur (Mappiare, 2013a: 117).

Kehadiran model konseling KIPAS adalah sebagai bagian dari budaya yang dimiliki oleh konseli/siswa maupun konselor/guru BK. Hal ini memaknai pentingnya konseling multikultural, karena baik konseli maupun konselor tidak terlepas dari pengaruh budaya. Konseling multikultural mutlak dilakukan dalam rangka untuk mereview sesi konseling yang peka budaya, konselor perlu mengetahui dan menghormati nilai-nilai tradisional dari kelompok etnis tertentu (Schoen, 2005: 253). Karenanya walaupun secara pribadi, manusia adalah unik namun tidak terlepas dari pengaruh budaya masyarakat (Efendi, dkk. 2009: 73).

Wacana konseling multikultural dipandang sebagai kekuatan terbesar keempat setelah konsep psikoanalisa, behaviorisme, dan konseling humanistik (Gladding, 2009: 100). Untuk itu konseling multibudaya perlu melakukan upaya-upaya seperti pelatihan keterampilan hubungan manusia, penyadaran budaya, dan pertemuan yang multi budaya dan lintas budaya (Gibson dan Mitchell, 2011: 319). 
Tentunya model KIPAS sudah termasuk didalamnya. Namun, akankah model KIPAS dapat menjawab permasalahan yang terjadi seperti banyaknya masalah siswa yang tidak terselesaikan dan perbaikan terhadap citra BK di masyarakat.

\section{HASIL DAN PEMBAHASAN}

Model KIPAS adalah sesuatu yang baru bagi konselor. Kemenarikan BK Model KIPAS adalah dijadikannya nilainilai budaya sebagai basis ataupun landasan dalam pelaksanaan pelayanan BK, sehingga memunculkan suatu pencerahan dalam pelaksanaan pelayanan BK di Nusantara ini. Awalnya disadari adanya permasalahan mengenai kekurangefektifan model-model konseling kerangka kerja para konselor sekolah beserta segala konsekuensinya. Ini berlanjut pada munculnya ide dasar yang melahirkan suatu studi heuristik mengenai model konseling multibudaya indonesia (Mappiare, 2013b: 37). Meskipun ini sebagai sebuah keunggalan dari sebuah model, tentu tidak tertutup kemungkin adanya sebuah kelemahan kalau boleh dibilang seperti itu.

Menurut pandangan kacamata dan pemahaman pribadi demi kemajuan pelayanan BK di nusantara ini agaknya perlu memberikan semacap kritik dan masukan terhadap model konseling berbasi budaya nusantara yaitu model KIPAS.
Mengingat model KIPAS boleh dikatakan baru dalam dunia BK, khususnya di Indonesia. Setiap hasil karya ciptaan manusia tentu tidak terlepas dari sisi kelebihan atau kekuatan dan sisi kekurangan atau kelemahan.

Tak dipungkiri lagi model konseling berbasis budaya nusantara model KIPAS ini memiliki beberapa kelebihan yaitu: pertama, keberadaan layanan BK model KIPAS yang berbasis pada budaya bangsa dan diramu melalui serangkaian "hasil riset ilmiah" secara nyata mengangkat martabat $\mathrm{BK}$, dan konselor Indonesia. Bagaimana tidak, yang selama ini kita tahu bahwa sudah sekian lama bahkan sampai sekarang pelaksanaan pelayanan $\mathrm{BK}$ di Indonesia masih menjadikan model-model yang ditawarkan oleh Barat menjadi rujukan. Mengingat masyarakat Indonesia lebih menganut budaya timur memiliki berbagai macam etnis dan budaya yang berbeda satu sama lain.

Palmer \& Laungani (2008: 97) berpendapat bahwa budaya-budaya barat menekankan individualisme, kognitifisme, bebas, dan materialisme, sedangkan budaya timur menekankan komunalisme, emosionalisme, determinisme, dan spiritualisme. Dengan adanya model KIPAS ini dengan sendirinya dapat mengangkat martabat $\mathrm{BK}$, dan konselor Indonesia. Perlahan-lahan BK, dan 
konselor Indonesia mulai memiliki keyakinan akan kekuatan sendiri. Tidak lagi bergantung pada konsep-konsep dari barat yang jelas-jelas itu kurang sesuai dengan kondisi dan keadaan budaya kita.

Kedua, layanan BK model KIPAS memiliki dasar filosofi yang jelas. Hal ini memudahkan para akademisi dan praktisi yang tertarik untuk memahami, memepelajari dan mengembangkan untuk diterapkan kepada siswa di sekolah sesuai dengan budaya setempat. Karena, idealnya BK dengan pendekatan budaya adalah membantu konseli untuk sesuai dengan norma yang ada pada diri dan di lingkungannya (Farida, 2016: 4).

Ketiga, prosedur yang dikemukakan oleh model KIPAS mendorong para konselor untuk aktif melakukan penyelidikan tentang standar pribadi konselor Indonesia. Bagaimanapun, Indonesia merupakan negara yang sangat plural. Oleh karena itu, standar untuk masing-masing sekolah adalah berbeda sesuai dengan kekhasan daeranya. Oleh karena itu tugas konselor sebagai seorang psychoeducator menurut Kartadinata (2011: 91) harus kompeten dalam memahami kompleksitas interaksi individu dengan lingkungan dalam ragam konteks sosial-budaya; intervensi intrapersonal dan interpersonal dan lintas budaya.
Keempet, model KIPAS menggunakan peristilah yang tidak asing dan sangat mudah untuk dikenal serta dipahami. Dengan kata lain istilah-istilah yang digunakan tidak banyak menggunakan istilah asing. Namaya diambil dari inisial yang disusun secara pantas, "Konseling Intensif Progresif Adaptif Struktur" (akronimnya, "KIPAS") (Mappiare, 2013a: 117). Semua itu memiliki makna-makna tersendiri dan tidak terlepas dari nilai-nilai budaya yang ada.

Kelima, unsur-unsur dan langkahlangkah dalam model KIPAS sangat mudah untuk diingat dan dilaksanakan karna merupakan akronim dari huruf yang ada dari kata "KIPAS". Unsur-unsur yang dimaksud adalah nama model, pemosisiandiri konselor, tema bahasan konseling, dan langkah-langkah konseling (Mappiare, 2017: 33). keempat unsur tersebut diakronimkan kedalam kata "KIPAS". Nama model diakronimkan sebagai Konseling Intensif Progresif Adaptif Struktur. Pemosisian-diri konselor diakronimkan sebagai Kawan Inovator Pamong Abdi Suporter. Tema bahasan konseling diakronimkan sebagai Karakter Identitas Pekerjaan Akademik Sosial. Sedangkan langkah-langkah yang dimaksud adalah dimulai dari Kabar gembira, Integrasi data dan internalisasi, Perencanaan tindakan, Aktualisasi rencana 
(tindakan) dan terakhir adalah Selebrasi/sertifikat untuk konseling yang kesemuanya juga merupakan akronim dari kata "KIPAS" (Mappiare, 2017: 42).

Keenam, model KIPAS berorientasi pada hasil dan proses, humanis, dan tidak mengedepankan konsep perfeksi. Manusia juga memiliki sifat yang unik, berbeda dengan makhluk lain dalam perkembangannya. Implikasi keragaman ini ialah bahwa individu memiliki kebebasan dan kemerdekaan untuk memilih dan mengembangkan diri sesuai dengan keunikan atas tiap-tiap potensi tanpa menimbulkan konflik dengan lingkungannya. Dari sisi keunikan dan keragaman individu, diperlukan bimbingan untuk membantu setiap individu mencapai perkembangan yang sehat di dalam lingkungannya. Pada dasarnya, BK juga merupakan upaya bantuan untuk menunjukkan perkembangan manusia secara optimal, baik secara kelompok maupun individu sesuai dengan hakikat kemanusiannya dengan berbagai potensi, kelebihan dan kekurangan, kelemahan serta permasalahannya (Salahudin, 2010: 43).

Ketujuh, model KIPAS adaptif terhadap struktur kerja sekolah yang penuh keterbatasan, terkait dengan durasi dan frekuensi wawancara. Disamping itu, model KIPAS memperhatikan struktur eksternal sekolah, dan sadar bahwa unit
BK adalah sebuah struktur. Ini terlihat dari konsep adaptif yang digunakan, yaitu sifat atau kondisi penuh dengan kemampuan melayani tuntutan-tuntutan struktur atau sistem (lingkungan), mencakup kepekaan, daya tanggap terhadap tuntutan lingkungan, daya sibernetik dan ekuilibrium diri, daya mampu mengubah sistem dalam diri untuk memenuhi tuntutan lingkungan atau struktur. Konseling seharusnya tidak terlalu bergantung pada dukungan sistem (system support); namun sebaliknya, diharapkan dapat menjadi sistem pendukung struktur di atas dan di bawahnya (Mappiare, 2017: 34).

Kedelapan, model KIPAS mendorong terciptanya kerjasama yang baik antara konselor dengan seluruh elemen sekolah dan hubungan yang harmonis antara konselor dengan siswa sejak dini. Sesuai dengan konsep yang digunakan dala posisi-diri konselor yaitu konsep Kawan. Dimana konselor memposisikan diri sebagai kawan atau teman bukan sebagai sesorang yang dituakan, namun disini lebih sebagai seorang sahabat. Apalagi dalam memberikan bantuan kepada siswa dalam menyelesaikan masalahnya. Konsep kawan atau teman ini sangat penting sekali. Siswa akan lebih sangat terbuka menyampaikan masalahnya kepada teman atau sahabat. Siswa membutuhkan afeksi dari siswa 
lainnya, dan membutuhkan kontak fisik yang penuh rasa hormat. Siswa juga membutuhkan perhatian dan rasa nyaman ketika mereka menghadapi masalah, butuh orang yang mau mendengarkan dengan penuh empati, serius, dan memberikan kesempatan untuk berbagi kesulitan dan perasaan seperti rasa marah, takut, cemas, dan keraguan (Cowie and Wallace, 2000). Artinya disini siswa akan lebih terbuka ketika konselor memposisikan dirinya sebagai teman bagi siswa, bukan sebagai orang yang dimintai bantuan dalam menyelesaikan masalahnya.

Kesembilan, model KIPAS sangat memperhatikan faktor akuntabilitas dari suatu pekerjaan yang selama ini mungkin sering dilupakan. Menurut Astramovich dan Coker (2007), akuntabilitas mempersyaratkan adanya evaluasi program karena melalui evaluasi program konselor dapat melakukan perencanaan dan pelaksanaan program yang lebih baik serta memperbaiki praktik BK. Akuntabilitas adalah cara dalam memberikan informasi kepada pihak-pihak lain di sekolah sertama syarakat tentang efektifitas pelayanan BK. Akuntabilitas memerlukan kegiatan sistemik dalam pengumpulan, analisis serta penggunaan data yang merupakan elemen penting dalam memahami perkembangan potensi konseli serta dalam merancang strategi untuk mengetahui efektifitas pelayanan dan mendokumentasikan tentang kontribusi program BK dalam mendukung keberhasilan siswa (Stone \&Dahir, 2003)

Sebagaimana yang telah dijelaskan dan perlu ditekankan lagi bahwa ini berdasarkan kacamata pribadi dimana sebagai sebuah model, konseling berbasi budaya nusantara model KIPAS tentu juga memiliki kekurangan. Pada tema bahasan dalam konseling telah berhasil diramu lima tema bahasan dalam konseling mengenai kepribadian konseli yang terdiri bidangbidang belajar, pekerjaan, dan sosial ditambah dengan karakter dan identitas. Disini tidak terdapat bidang keberagamaan, sementara ini adalah hal yang sangat urgen untuk saat ini. Alangkah tepatnya karakter dijadikan keberagamaan, karena secara tidak langsung keberagamaan akan membentuk karakter. Artinya individu yang beragama tentu memiliki karakter tersendiri dalam dirinya. Peran pendidikan agama khususnya pendidikan agama Islam sangatlah strategis dalam mewujudkan pembentukan karakter siswa. Pendidikan agama merupakan sarana transformasi pengetahuan dalam aspek keagamaan (aspek kognitif), sebagai sarana transformasi norma serta nilai moral untuk membentuk sikap (aspek afektif), yang berperan dalam mengendalikan prilaku (aspek psikomotorik) sehingga 
tercipta kepribadian manusia seutuhnya (Ainiyah, 2013: 26).

Istilah karakter dihubungkan dan dipertukarkan dengan istilah etika, ahlak, dan atau nilai dan berkaitan dengan kekuatan moral, berkonotasi "positif" bukan netral (Dirjen Pendidikan Tinggi Kemendiknas, 2010: 9). Oleh karena itu Pendidikan karakter secara lebih luas dapat diartikan sebagai pendidikan yang mengembangkan nilai budaya dan karakter bangsa pada diri peserta didik sehingga mereka memiliki nilai dan karakter sebagai karakter dirinya, menerapkan nilai-nilai tersebut dalam kehidupan dirinya sebagai anggota masyarakat, dan warga negara yang religius, nasionalis, produktif, dan kreatif. Hal ini juga sejalan dengan amanat undang-undang Nomor 20 tahun 2003 tentang sistem pendidikan nasional, dimana pendidikan karakter menempati posisi yang paling penting.

\section{Sumbangsih Model KIPAS terhadap Pengentasan Masalah Siswa}

Melihat kepada banyaknya masalah siswa yang tidak terentaskan, model KIPAS memberikan sumbangsih terhadap pelaksanaan layanan BK diantaranya: pertaman, layanan BK model KIPAS dirasakan memiliki prospek ke depan yang lebih cerah bagi pengentasan masalah konseli/siswa. Sangat imajinatif, sehingga sangat mudah untuk dipahami dalam menghadapi berbagai masalah konseli.
Kedua, model KIPAS berbasis pada nilai-nilai budaya. Artinya dalam pelaksanaannya mempertimbangkan budaya setempat. Ini sangat tepat sekali dalam penyelesaian masalah yang sesuai dengan kondisi budayanya. Sangat berbeda dengan model yang selama ini dipakai yang landasannya pada budaya barat yang sudah bara pasti tidak sesuai dengan budaya kita. Hoopes (dalam Vacc et al, 2003) menyebutkan bahwa sebagian besar resolusi kesulitan dalam berkomunikasi terletak pada pemahaman terhadap culture code (kode budaya) yang terjadi. Hal ini menurutnya dapat mempengaruhi interaksi manusia.

Shiraev \& Levy (2010) mengemukakan bahwa emosi atau afeksi merupakan suatu respon untuk mengevaluasi beberapa kombinasi rangasangan fisiologis, pengalaman subyektif (baik itu positif, negative atau hal-hal yang bertentangan) dan ekspresi perilaku. McLeod (2003) menyebutkan bahwa ekspresi emosi merupakan salah satu enkulturasi yang sangat penting dalam konseling. Kultur yang berbed a melahirkan beragam pemahaman terhadap emosi mana yang dapat ditermima dan ekspresi mana yang diizinkan untuk dilakukan di depan publik. Sue \& Sue (1990) menyebutkan bahwa ekspresi emosi dalam konseling dan psikoterapi merupakan sebuah tujuan dan juga sangat diinginkan. Namun, terdapat 
beberapa kelompok budaya yang menganggap bahwa pengendalian emosi yang kuat merupakan hal yang disukai. Bila konselor tidak memahami perbedaan yang ada, maka kemungkina dapat timbul misperception dan mis understanding antara keduanya.

Kedua model KIPAS terbuka terhadap hubungan kerjasama dan kolaborasi antar dan interprofesi. Modelmodel konseling yang tersedia selama ini cenderung abai terhadap pentingnya kerjasama dan kolaborasi antara konselor dengan semua elemen yang ada di sekolah. Hal ini penting, karena dalam penyelesaian suatu permasalahan membutuhkan pihak lain. Setiap permasalahan yang terjadi pada siswa, itu semata-mata bukan tanggung jawab konselor atau guru BK. Konselor merupakan salah satu bagian dari tenaga pendidik yang cukup besar peranannya dalam penyelenggaraan pendidikan. Konselor sekolah memang bukan satu-satunya pihak yang harus bertanggung jawab atas terjadinya fenomena tersebut (Batuadji, 2015: 18). Namun tidak dapat dipungkiri, ternyata hingga saat ini masih banyak permasalahan yang timbul di lembaga-lembaga pendidikan, di mana peran profesi konselor tampaknya belum memadai. Semua itu perlu keterlibatan semua elemen-elemen yang ada.

\section{Sumbangsih Model KIPAS terhadap Perbaikan Citra BK}

Menghadapi berbagai persepsi negatif terhadap pelaksanaan BK, model KIPAS memberikan sumbangsih, diantaranya; pertama, konselor yang dikategorikan sebagai bermartabat yaitu memiliki citra-citra derajat sosial yang diperoleh dari pola perilaku yang tenang atau sungguh-sungguh dalam kualitas (pribadi) yang berharga atau memiliki kehormatan dalam jenjang posisi yang dapat dihargai dan diperlakukan secara khusus karena dia orang yang penting. Suatu citra bermartabat bagi konseling Indonesia harus disandarkan pada konteks sosial-budaya Nusantara. Semua itu terd apat pada model KIPAS.

Kedua, konseling Indonesia harus memiliki identitas diri sendiri. Kehadiran model KIPAS merupakan upaya mengukuhkan martabat konselor dan konseling Indonesia yang selama ini masih berkiblat pada budaya barat. Budayabudaya barat menekankan individualisme, kognitifisme, bebas, dan materialisme, sedangkan budaya timur menekankan komunalisme, emosionalisme, determinisme, dan spiritualisme (Palmer, 2008: 97).

Ketiga, citra konseling Indonesia semakin bagus, perlu dilakukan upaya pengembangan secara terus-menerus terhadap gubahan model KIPAS. Di 
samping itu, perlu juga dilakukan pengembangan model-model konseling lain yang berbasis pada budaya nusantara. Sebagaimana penelitian yang dilakukan oleh Zubaidah (2014: 215) yaitu menggali nilai-nilai pepatah Minangkabau dalam konseling, hal ini terlihat dari nilai-nilai pepatah Minangkabau dalam memandang hakekat manusia, nilai-nilai pepatah Minangkabau dalam memandang hakekat masalah, nilai-nilai pepatah Minangkabau dalam memandang hakekat prosedur penyelesaian masalah, dan nilai-nilai pepatah Minangkabau dalam memandang hakekat seorang pemimpin (konselor). Ini merupakan salah satu bentuk langkah dalam upaya pengembangan model-model konseling yang berbasis pada budaya nusantara dan sekaligus akan membangun citra positif terhadap konseling di Indonesia.

\section{Keempat, model KIPAS} memposisikan konselor sebagai kawan bagi konseli/siswa. Konsep ini sangat efektif dalam menjalin hubungan dengan konsli/siswa. Kawan yang senantiasa selalu memberikan membantu atau selalu meberi pertolongan. Bila seorang guru pembimbing mampu bersikap menerima murid yang menghadapi masalah, dia memiliki kapasitas untuk menjadi “penolong” yang efektif. Menerima murid seperti apa adanya merupakan faktor penting untuk meningkatkan hubungan guru dengan murid, karena apabila seseorang merasa diterima kemudian dipahami oleh orang lain maka orang itu akan bergerak lebih bebas dan mulai berfikir untuk mengubah dirinya sendiri menjadi lebih baik dari pada yang dialami sekarang. Sebaliknya, sikap pembimbing yang tidak menerima murid apa adanya mendorong mereka menjadi tertutup, bersikap defensif, takut berbicara dan merasa tidak senang (Gordan, 1984: 69). Dengan demikian secara tidak langsung akan merobah pandangan yang selama ini kurang baik terhadap konselor.

\section{KESIMPULAN}

Model KIPAS menjadikan nilainilai budaya Nusantara sebagai landasannya. Konseling berbasis budaya Nusantara model KIPAS ini memiliki beberapa kelebihan yaitu; (1) layanan BK model KIPAS yang berbasis pada budaya bangsa diramu melalui hasil riset dan dapat mengangkat martabat $\mathrm{BK}$, dan konselor Indonesia. (2) Layanan BK model KIPAS memiliki dasar filosofi yang jelas. (3) Prosedur layanan model KIPAS mendorong para konselor untuk aktif melakukan penyelidikan tentang standar pribadi konselor Indonesia. (4) Unsurunsur dan langkah-langkah dalam model KIPAS sangat mudah untuk diingat dan dilaksanakan karna merupakan akronim dari huruf yang ada dari kata "KIPAS". (6) 
Model KIPAS berorientasi pada hasil dan proses, humanis, dan tidak mengedepankan konsep perfeksi. (7) Model KIPAS adaptif terhadap struktur kerja sekolah yang penuh keterbatasan, terkait dengan durasi dan frekuensi wawancara. (8) Model KIPAS mendorong terciptanya kerjasama yang baik antara konselor dengan seluruh elemen sekolah dan hubungan yang harmonis antara konselor dengan siswa sejak dini. (9) Model KIPAS sangat memperhatikan faktor akuntabilitas dari suatu pekerjaan yang selama ini mungkin sering dilupakan.

Model KIPAS memberikan sumbangsih terhadap pelaksanaan layanan BK diantaranya adalah (1) Layanan BK model KIPAS dirasakan memiliki prospek ke depan yang lebih cerah bagi pengentasan masalah konseli/siswa. (2) Model KIPAS berbasis pada nilai-nilai budaya. Artinya dalam pelaksanaannya mempertimbangkan budaya setempat. (3) Model KIPAS terbuka terhadap hubungan kerjasama dan kolaborasi antar dan interprofesi.

Menghadapi berbagai persepsi negatif terhadap pelaksanaan BK, model KIPAS memberikan sumbangsih, diantaranya adalah (1) Suatu citra bermartabat bagi konseling Indonesia harus disandarkan pada konteks sosialbudaya Nusantara. Semua itu terdapat pada model KIPAS. (2) Kehadiran model
KIPAS merupakan upaya mengukuhkan martabat konselor dan konseling Indonesia yang selama ini masih berkiblat pada budaya barat. (3) Agar citra konseling Indonesia semakin bagus, perlu dilakukan upaya pengembangan secara terus-menerus terhadap gubahan model KIPAS. (4) Model KIPAS memposisikan konselor sebagai kawan bagi konseli/siswa. Konsep ini sangat efektif dalam menjalin hubungan dengan konsli/siswa.

\section{DAFTAR PUSTAKA}

Ainiyah, Nur. (2013). Pembentukan Karakter Melalui Pendidikan Agama Islam. Jurnal Al-Ulum, 13 (1) 25-38.

Astramovich, R. L. \& Coker, J. K. (2007). The accountability bridge model for counselors. Journal of Counseling and Development, 85, 162-172.

Batuadji, K., Atamimi, N., Sanmustari, R. B. (2015). Hubungan Antara Efektivitas Fungsi BK Dengan Persepsi Siswa Terhadap BK di Sekolah Menengah Pertama Stella Duce I Yogyakarta. Jurnal Psikologi, 36 (1) 18-34.

Cowie, H., dan Wallace, P. (2000). Peer Support in Action: From Bystanding to Standing By. London: Sage Publications.

Dirjen Pendidikan Tinggi Kemendiknas. (2010). Kerangka Acuan Pendidikan Karakter.

Efendi, Lalu Muchsin dan Faizah. (2009). Psikologi Dakwah. Jakarta: Kencana.

Farida. (2016). Bimbingan Konseling Agama dengan Pendekatan 
Budaya. Konseling Religi, 7 (1) 130.

Gibson, R. L. dan Mitchell, M. H. (2011). $B K$. (Alih Bahasa: Yudi Santoso).

Gladding, S. T. (2009). Konseling Profesi yang Menyeluruh. Pengalih bahasa (P.M. Winarno dan Lilian Yuwono). Jakarta: Indeks.

Kartadinata, S. (2011). Kerangka Kerja BK dalam Pendidikan: Pendekatan Ekologis Sebagai Alternatif. Bandung: UPI Press.

Mappiare-AT, A. (2013a). Penguatan Layanan BK Melalui Model Konseling Intensif dan Progresif yang Adaptif terhadap Struktur (KIPAS). Proceeding Seminar Internasional Forum FIP-JIP SeIndonesia, Medan, 29-31 Oktober 2013. Medan: UNIMED Press.

Mappiare-AT, Andi. (2013). Martabat Konselor Indonesia dalam Falsafah dan Kinerja Model KIPAS: Konseling Intensif Progresif Adaptif Struktur. Prosiding Kongres XII, Konvensi Nasional XVIII ABKIN dan Seminar Internasional Konseling, Denpasar Bali, 14 s.d 16 November 2013. Denpasar: Panitia Kongres XII, Konvensi Nasional BK XVIII.

Mappiare-AT, Andi. (2017). Meramu Model Konseling Berbasis Budaya Nusantara: KIPAS (Konseling Intensif Progresif Adaptif Struktur). Pidato Pengukuhan Jabatan Guru Besar dalam Bidang Ilmu Budaya Konseling pada Fakultas Ilmu Pendidikan. Disampaikan pada Sidang Terbuka Senat Universitas Negeri Malang Tanggal 28 Februari 2017.
McLeod, John. (2003). Pengantar Konseling: Teori dan Studi Kasus. Kencana, Jakarta.

Palmer, S dan Laungani, P. (2008). Counseling in a Multicultural Society. London: Sage Publisher.

Prayitno dan Erman Amti. (1994). Dasardasar BK. Jakarta: Rineka Cipta.

Salahudin, 2010, BK, Bandung: Pustaka Setia.

Schoen, A. A. (2005). Culturally Sensitive Counseling for Asian Americans/ Pasific Islanders. Journal of Instructional Psychology. 32 (3) 253-258.

Shiraev, Eric B., Levy, David. (2010). Cros-Cultural Psychology. Allyn \& Bacon, USA.

Stone, C. B. dan Dahir, C. A. (2003). Accountability: A M.E.A.S.U.R.E. of the impact school counselors have on student achievement. Professional School Counseling, 6, 214-222.

Undang-Undang No. 20 Tahun 2003. Tentang Sistem Pendidikan Nasional.

Vacc, N., DeVaney, S., Brendel, J. (2003). Counseling Multicultural and Diverse Populations: Strategies for Practitioners. Brunner-Routledge, NY, USA.

Walgito, Bimo. 2004. BK (Study dan Karir), Yogyakarta: PT. CV. Andi Offset.

Zubaidah. (2014). Telaah Nilai-nilai Pepatah Minangkabau dan Kontribusinya dalam Konseling. Tesis tidak diterbitkan. Malang: Pascasarjana UM. 